\title{
A CONTRIBUIÇÃO IBEROBRASILEIRA PARA 0 APERFEIÇOAMENTO DA EMPRESA INDIVIDUAL \\ DE RESPONSABILIDADE LIMITADA
}

\section{Adalberto Simão Filho}

Mestre e Doutor em direito das relações sociais pela PUC/SP. Pós-doutor pela Faculdade de Direito da Universidade de Coimbra-Portugal. Professor Titular IV com grau de Professor Emérito das Faculdades Metropolitanas Unidas -FMU/SP. Professor do programa de mestrado da Universidade de Ribeirão Preto-UNAERP/ SP. Acadêmico, membro de número da Inter American Academy of International and Comparative Law. Árbitro designado pelo CAESP- Conselho de Arbitragem do Estado de São Paulo e sócio diretor de Simão Filho - Advogados Associados.

\section{Resumo}

Este artigo pretende avaliar as contribuiçóes colhidas na experiência espanhola de criação do modelo denominado Sociedade Limitada Nova Empresa - SLNE que foi introduzida no ordenamento pela Ley $7 / 2003$ que permite a integração de pessoa natural única em seus quadros e facilita a atividade mercantil a partir de seus registros. Escolhendo temas de relevo, o modelo espanhol foi confrontado com o modelo desenvolvido pela legislação brasileira - Lei no 12.441, de 11 de julho de 2011 para a criação da Empresa Individual de Responsabilidade Limitada - Eireli, apresentando-se as principais características de cada qual e evoluçóes.

\section{Palavras-chave}

Nova empresa; Responsabilidade limitada; Sociedade; Empresa.

\section{Resumen}

Este artículo tiene como objetivo evaluar las contribuciones recogidas en la experiencia española de crear la denominada sociedad de responsabilidad limitada Nueva Empresa modelo - SLNE que se introdujo con el fin de la Ley 7/2003, que permite la integración de la persona física única y facilita actividades de negocio de sus registros. La elección de los temas pertinentes, el modelo español se enfrentó con el modelo desarrollado por la legislación brasileña - Ley $\mathrm{N}^{\circ} 12.441$, de 11 de julio de 2011 para la creación de empresa individual de Responsabilidad Limitada - EIRELI, presentando las principales características de cada uno y desarrollos. 


\section{Palabras clave}

Nueva empresa; Sociedad de responsabilidad limitada; Sociedad empresa.

\section{Introdução}

A Espanha, visando propiciar um ambiente de crescimento da atividade empresarial onde se contemplasse não só a redução de burocracias registrarias como também a possibilidade do exercício de atividade de forma individual, todavia com responsabilidade limitada, fez editar a Lei 7/2003, de $1^{\circ}$ de abril que regulou a SLNE - Sociedad Limitada Nueva Empresa com personalidade jurídica distinta de seu sócio ou sócios, capital social dividido em participaçóes indivisíveis e, independente de sua ativiade, sempre terá o caráter mercantil

Não há um número mínimo de sócios, podendo desde o nascimento ser a mesma constituída de forma unipessoal. O limite de sócios fundadores é cinco, podendo ser ampliado no futuro. Somente se admite sócios-pessoas físicas e a responsabilidade pelas dívidas sociais é limitada ao capital aportado.

Trata-se assim, a SLNE, de uma especialidade no âmbito das Sociedades de Responsabilidade Limitada na Espanha, constituída por escritura pública lavrada em notário e inscrita no Registro mercantil.

Este artigo pretende efetuar uma análise comparativa dos dois sistemas legais voltados para as atividades empresariais com limitação de responsabilidade, com vistas a apresentar eventuais colaboraçóes ao instituto da sociedade individual/

Os tipos sociais previstos no sistema brasileiro consistem na sociedade em nome coletivo, sociedade em conta de participação, sociedade em comandita simples, sociedade por açóes, sociedade em comandita por açóes e sociedade limitada, diferenciando-se estes tipos entre si, pela forma de administração da sociedade e a limitação ou não da responsabilidade dos sócios por obrigaçóes sociais.

$\mathrm{Na}$ organização da atividade mercantil no Brasil, desenvolveram-se também, as políticas de proteção de micro e pequenas empresas e empreendedores individuais, através de preceito constitucional e do estabelecimento de regimes jurídicos específicos que disciplinam acerca dos benefícios destinados às mesmas e âmbito de responsabilidade dos sócios ou do empresário pelas obrigações sociais contraídas.

A responsabilidade da pessoa que faz a opção de explorar de forma individual a atividade econômica, quer como empresária individual ${ }^{1}$, ou microempreendedor individual ${ }^{2}$, é ilimitada nas obrigaçóes contraídas socialmente.

1 Nos moldes do art. 966 do Código Civil.

2 Na forma estatuída pelo art. 18-a da Lei Complementar n.123/206. 
Excepcionalmente no Brasil, há casos em que as sociedades de responsabilidade limitada, acabam por restar unipessoal sem que deste fato se possa depreender que a responsabilidade do sócio único seja automaticamente transformada em ilimitada..A subsidiária integral tendo como única acionista uma sociedade brasileira, possui previsão no art. 251 da Lei 6.404/76. Por outro lado, ocorrências pontuais que possam refletir diretamente no quadro social como o falecimento ou despedida de sócio ou a extinção da personalidade jurídica para com relação a um sócio, também contribuem para que a sociedade de qualquer natureza ou tipo, possa restar apenas com um único sócio no seu quadro.

Dispóe o Código Civil brasileiro que nas sociedades contratuais, a pluralidade de sócios deve ser restituída no prazo de 180 (cento e oitenta) dias (art. 1.033 - IV) e, por sua vez, nas sociedades por açóes, na ocorrência de restar por qualquer motivo com um acionista único, o quadro social deve ser restituído e completado até a próxima assembleia ordinária ${ }^{3}$.

Uma nova modalidade de pessoa jurídica de direito privado é então formada pela empresa individual de responsabilidade limitada, ocupando um espaço no cenário brasileiro, alem daquelas já existentes como associações, sociedades, fundaçôes, partidos políticos e entidades religiosas.

\section{Os Regimes Jurídicos Comparativos}

A Empresa Individual de Responsabilidade Limitada - Eireli foi criada pela Lei $\mathrm{n}^{\circ}$ 12.441, de 11 de julho de 2011 publicada no Diário Oficial da Uniáo de 12/07/2011 que alterou a Lei no 10.406 , de 10 de janeiro de 2002 (Código Civil) a partir da inserçáo do art. 980-A.

Foi assim criada a empresa individual de responsabilidade limitada, com a previsão de sua constituição por uma única pessoa titular da totalidade do capital social, devidamente integralizado, que não será inferior a 100 (cem) vezes o maior salário-mínimo vigente no pais.

Este regime jurídico favorecido da Eireli é o mesmo adotado para as microempresas e empresas de pequeno porte consoante previsão do art. $3^{\circ}$ da lei Complementar 139/11, aplicando-se, no que couber, as regras previstas para as sociedades limitadas.

Como asseveram Paulo Cesar Aragão e Gisela Sampaio da Cruz ${ }^{4}$ o direito brasileiro fez previsão de duas formas de constituição de Eireli, que podem ser classificadas como

3 As Assembleias Ordinárias no Brasil, realizam-se uma vez ao ano, via de regra, nos quatro primeiros meses do ano.

4 Aragáo. Paulo Cesar e Gisela Sampaio da Cruz. Empresa individual de responsabilidade limitada:O "moderno Prometheus" do direito societário. Publicado na obra Empresa individual de Responsabilidade 
originária ou direta, com base no caput do art-980-A, criada sem a existência de ente anterior e a derivada ou indireta como disposto no parágrafo $3^{\circ}$ do art.980-A e art. 1033 parágrafo único, resultante da conversão ou transformação de uma sociedade de outro tipo social em Eireli.

Já na experiência espanhola a Sociedade Limitada Nova Empresa- SLNE foi introduzida pela Ley 7/2003 como forma simplificada das sociedades limitadas decorrente deste novo regime societário mais sensível e dinâmico do que o antigo.

A Ley 24/2005 de 18 de novembro que foi editada com o objetivo de impulsionar a produtividade empresarial, introduziu modificações na legislação da nova empresa no que tange a sua denominação social, dando liberdade aos sócios de criarem razão social na forma como for conveniente aos mesmos.

A sociedade limitada nova empresa possui personalidade jurídica própria e caráter mercantil, independente de sua natureza específica e de seu objeto, como se observará. .

\section{Função Econômica do Instituto}

A SLNE foi criada na Espanha como mais uma opção válida para desburocratizar a atividade mercantil e atrair empresários ao seu modelo, inclusive para que, de forma individual e com limitação de responsabilidades, pudessem assumir os riscos da atividade e contribuir para o crescimento do pais.

Já no Brasil, a Eireli foi idealizada tanto para a produção ou circulação de bens, como de serviços e terá personalidade jurídica a partir de registro no órgão próprio (vide art. 44.VI do Cód. Civ), gerando todos os efeitos pertinentes à personalização, inclusive o de distinção patrimonial. A empresa individual de responsabilidade limitada também poderá resultar da concentração das quotas de outra modalidade societária num único sócio.

Do ponto de vista de sua função econômica, a Eireli representa mais uma via de acesso à atividade empresarial e ao empreendedorismo e a possibilidade real de racionalização da gestấo das sociedades quando o seu quadro social tenha se reduzido a apenas um sócio, possibilitando o fomento da atividade mercantil, regularização e/ou criação de empresas unipessoais, contribuindo para o crescimento e desenvolvimento social com o auxílio na circulação da riqueza, no âmbito circunscrito de sua operação.

Como preleciona Maurício Andere Von Bruck Lacerda5, esta nova figura jurídica poderá se prestar a ser uma alternativa válida para a viabilização da atividade empresarial

Limitada-Eireli- Aspectos econômicos e legais, organizada por Pedro Anan Junior e Marcelo Magalhães Peixoto.MP Editora. São Paulo, 2012, pag. 219.

5 In Empresa Individual de responsabilidade Limitada- Eireli. Desafios e Perspectivas, artigo publicado na Revista eletrônica FMU - Direito, ano 27, n. 39, p.151 -..2013. 
com limitação de responsabilidade tanto aos que pretenderem nela se iniciar, como aos pequenos empreendedores, afastando a necessidade de constituição de sociedades pro forma, apenas para cumprir a pluralidade do quadro social, numa situação nefasta àquela pessoa que apenas detinha participaçáo social ilusória, na medida em que acabava por correr todos os riscos fiscais, ambientais, trabalhistas e civis, inerentes à atividade empreendida, sem qualquer chance de defesa. $\mathrm{O}$ advento da Eireli pode também se prestar a ser forte elemento de atração de empresários informais para a regularidade, gerando efeitos benéficos à população a partir do cumprimento das obrigaçóes empresariais inerentes ao exercício desta atividade.

A vocação ao empreendedorismo, como anota Francisco Dornelles ${ }^{6}$, atende também à num modelo de negócio que prescinda de um sócio e proteja o patrimônio individual do empresário, oferecendo um inédito ambiente de segurança jurídica e mercadológica.

\section{Sócios e Titularização da Empresa}

A SLNE pode ser criada na Espanha a partir de um único sócio, pessoa física, sob forma de sociedade unipessoal. Todavia, não pode constituir ou adqurir a condição de sócio único de uma SLNE aquele que já tenha titularizado outra sociedade da mesma natureza.

Por outro ângulo, a fundação da SLNE pode ser efetivada por até cinco sócios pessoas físicas no primeiro momento, podendo este quadro ser ampliado em momentos posteriores.

Este fato se dá porque neste modelo espanhol, a transmissão das participaçóes sociais somente pode se dar a pessoas físicas . Desta forma, em razão deste regime de cessão de participaçóes societárias, poderá ocorrer que várias outras pessoas físicas adquiram quotas sociais, passando a integrar um quadro societário superior a cinco pessoas,

Caso porventura, em razáo de negócio jurídico, uma pessoa jurídica tenha adquirido participaçóes societárias deste modelo social, deverá a mesma transferi-las de alguma forma para a pessoa física que adquirirá o sttatus de sócia, no prazo de três meses.

Nenhum destes sócios responderá pelas dívidas sociais, estando limitada a sua responsabilidade ao capital social devidamente integralizado.

6 Dorneles. Francisco. Novas perspectivas para os empreendedores brasileiros. Publicado na obra Empresa individual de Responsabilidade Limitada-Eireli- Aspectos econômicos e legais, organizada por Pedro Anan Junior e Marcelo Magalhães Peixoto.MP Editora. São Paulo, 212, pag.83. O Autor - na qualidade de Senador da República, foi Relator na Comissão de Justiça e Cidadania (CCJ) do Senado Federal, do projeto de Lei da Câmara n. 18 de 2011, de autoria do Deputado Marcos Montes que foi aprovado e convertido na Lei 12.441/2011. 
No Brasil há entendimento do DNRC- Departamento Nacional de Registro do Comércio no sentido de que somente a pessoa natural pode ser titular de Eireli, desde que esta não seja impedida por norma constitucional ou por lei especial. O titular de Eireli será a pessoa natural, maior de 18 anos, brasileiro ou estrangeiro, que se achar na livre administração de sua pessoa e bens, ou, ainda, o menor emancipado na forma da lei, desde que não haja impedimento legal.

Alfredo de Assis Gonçalves Neto ${ }^{7}$ menciona que, muito embora o art.980-A utilize a expressão "pessoa" em exclusão do termo "natural" que figurava no projeto original, o parágrafo $2^{\circ}$, ao proibir a criação de mais de uma empresa individual de responsabilidade limitada por "pessoa natural", completa-o, deixando claro que é exclusivamente a esta que se refere o caput.

Para este Autor, se a norma pudesse ser interpretada no sentido de permitir a criação da Eireli por pessoas jurídicas, não haveria coerência lógica em se restringir a criação deste ente para apenas uma pessoa.

A Instrução Normativa n.117 do DNRC dispóe no item 1.2.11, por sua vez, que a pessoa jurídica não pode ser titular de Eireli e a Instrução Normativa DNRC n. 118 de 22 de novembro de 2011 que dispóe sobre o processo de transformação de registro de empresário individual em sociedade empresaria contratual, ou em empresa individual de responsabilidade limitada e vice-versa, preconiza em seu art. $3^{\circ}$ que a transformação de registro de empresário em sociedade ou em empresa individual de responsabilidade limitada e vice-versa não abrange as sociedades anônimas, sociedades simples e as cooperativas. $\mathrm{O}$ art. $4^{\circ}$ a Instrução Normativa complementa que a sociedade em condiçáo de unipessoalidade poderá ter seu registro transformado para empresário individual, independentemente do decurso do prazo de cento e oitenta dias, desde que não realizada a liquidaçáo decorrente da dissolução a que se refere o inciso IV do art. 1.033 do Código Civil.

Fábio Ulhoa Coelho ${ }^{8}$ apresenta interessante posicionamento no sentido de que a proibição de titularização de mais de uma empresa deste tipo, só se dá com relação ao sócio único pessoa física.

Este conflito de posiçóes faz parte da discussão atual do tema no Brasil. Na V- Jornada de Direito Civil foi aprovado o Enunciado 467 com a orientação de que " $A$ empresa individual de responsabilidade limitada só poderá ser constituida por pessoa natural." $\mathrm{Na}$ I-Jornada de Direito Comercial promovida pelo Centro de Estudos Judiciários do Conselho da Justiça Federal de 2012, a proposta de permissão de criação de Eireli por pessoa

7 GONÇALVES NETO. Alfredo de Assis. Direito de empresa. São Paulo:Revista dos Tribunais, 4a Ed.2014, pag. 129. O autor entende que a expressão individual remete a individuo que, no contexto, significa ser pertencente à espécie humana.

8 Coelho. Fabio Ulhoa. Curso de Direito Comercial. Saraiva: São Paulo. 2014, pag. 409. 
jurídica, foi rejeitada. Todavia, na I-Jornada Paulista de Direito Comercial promovida pelo IASP, foi aprovado o Enunciado 3 que dispóe "A Empresa Individual de Responsabilidade Limitada pode ser constituida por pessoa jurídica."

Partindo do principio da isonomia como vetor interpretativo do parágrafo $2^{\circ}$ do art. 980-A, Marcio Tadeu Guimarães Nunes contesta a interpretação adotada pelo DNRC no sentido de que a Eireli só possa ser criada por pessoa natural, defendendo também o interessante ponto de vista liberal já descrito, onde explica que pode a pessoa jurídica titularizar múltiplas Eirelis e a pessoa humana apenas um ente desta natureza.

Somos da opiniáo professada pela parte da doutrina que entende que ao se generalizar no caput do art. 980-A que a empresa individual de responsabilidade limitada será constituída por uma única pessoa titular da totalidade do capital social, pretendeu o legislador, conceder oportunidades reais para pessoas jurídicas que sejam titulares de sociedades de outros tipos sociais e que porventura tenham se tornado unipessoal por qualquer motivo, que possam constituírem-se em Eireli titularizada por esta.

Ainda, nada obstará, em razão da não especificação da espécie de pessoa, como mencionou Fabio Ulhoa Coelho, que se possa constituir primariamente uma Eireli por uma pessoa jurídica que não seja fundação, associação, ou seja, uma pessoa jurídica empresaria que, inclusive, poderá concentrar as quotas de outra modalidade societária num único sócio, independente das razôes que motivaram esta concentração, como expressa o parágrafo $3^{\circ}$ do art. 980-A

Há também quem entenda não só que a pessoa jurídica possa compor uma Eireli, como também que há viabilidade de a sociedade estrangeira compor a titularidade deste ente social como disciplina Charles William Macnaughton ${ }^{10}$. Todavia, se isto acontecer, deve-se observar que o Manual dos atos de Registro de Empresa Individual de Responsabilidade Limitada editado pelo DNRC, ao permitir que pessoa natural estrangeira seja titular de EIRELI no item 1.2.10, contribui para uma interpretação no sentido de que o estrangeiro possa representar a empresa estrangeira que titularizará a Eireli, mesmo não

9 Nunes. Márcio Tadeu Guimarães. EIRELI- A Tutela do patrimônio de afetaçấo. Quartier Latins. São Paulo. 2014, pag.124. Aliás, traz o Autor no que denominou de caso Purpose Brazil LLc e Purpose Campaings Brasil Ltda.Vs.Jucerja a decisão liminar proferida em 07 de março de 2012 pela Juíza Gisele Guida de Faria, da 9a Vara da Fazenda Pública do Rio de Janeiro, em mandado de segurança n. 0054566-71.2012.8.19.0001 onde se determinou à autoridade impetrada Junta Comercial, que mantivesse a singularidade acionária da $2^{\mathrm{a}}$ impetrante, sem qualquer risco de dissolução, admitindo, com base no principio constitucional da legalidade máxima, que a pessoa jurídica titularizasse a Eireli, mencionando que não cabia ao DNRC normatizar a matéria inserindo proibição não prevista em lei. O caso é interessante por tratar de duas pessoas jurídicas sendo uma brasileira e uma estrangeira que pretendiam constituir uma Eireli. Esta liminar ainda vigorava em 19.03.2013 segundo o Autor. Pag.103.

10 Macnaughton. Charles William, in Titular estrangeiro na Eireli. Publicado na obra Empresa individual de Responsabilidade Limitada-Eireli- Aspectos econômicos e legais, organizada por Pedro Anan Junior e Marcelo Magalhães Peixoto.MP Editora.São Paulo, 2012, pag.63. 
sendo residente no pais, desde que nomeie o representante no pais com poderes para o recebimento de citação.

O limitador à pessoa natural como descrito no parágrafo $2^{\circ}$ do art. 980-A., nesta ótica, seria apenas e táo só para que se evitasse a constituiçáo de um agrupamento empresarial de Eirelis por pessoas naturais.

\section{Natureza Jurídica Específica}

A SLNE espanhola possui clara natureza jurídica societária impregnada no âmbito da lei que a criou, mesmo quando este modelo é composto por unicamente um sócio.

Nesta condição, a Ley 7/2003 acaba por se afastar do regime brasileiro que ainda não se definiu do ponto de vista interpretativo, se a Eireli é um novo modelo social ou uma espécie de sociedade ou, ainda, apenas uma atividade empresária.

A aplicabilidade das regras específicas de direito societário nas SLNE gera mais segurança ao modelo e possibilita a avaliação do risco da oportunidade ao passo em que a ambivalência da lei brasileira, como será demonstrada a seguir, gera insegurança jurídica e contribui para que as situaçóes que possam envolver a Eireli se resolvam somente através de sistema interpretativo judicial ou arbitral, o que não é desejável ao ambiente de negócios que se pretende formar em países desenvolvidos, como forma de contribuição para a sua expansão econômica.

Parece que contribui para a incerteza interpretativa e dificuldade da compreensão real da natureza deste instituto e de seu alcance no Brasil, o fato de a legislação ter-se dissociado do projeto de lei originário sobre a Eireli que foi apresentado com 28 artigos que, na aprovação se transformaram em um único artigo com seis parágrafos,

Já observou Ana Claudia Pastore em outra oportunidade ${ }^{11}$, que esta imprecisão legislativa acabou por gerar não só problemas sérios relativos à constituição e formação deste ente personalizado, como também um aquecido debate doutrinário que será aqui apenas sintetizado, acerca da Eireli ser uma espécie de pessoa jurídica distinta das sociedades ou uma nova modalidade societária.

A Eireli possui natureza de sociedade limitada como apregoa Fábio Ulhoa Coelho ${ }^{12}$ , dando-se o caráter de responsabilidade limitada mesmo que unipessoal, podendo esta ser constituída tanto por sócio único pessoa física, como por uma pessoa jurídica.

11 Pastore, Ana Claudia et Simão Filho. Adalberto. In Aplicabilidade da convenção arbitral no âmbito da empresa individual de responsabilidade limitada. Artigo publicado na obra Empresa Individual de Responsabilidade Limitada- EIRELI- Aspectos Econômicos e legais, org. Pedro Anan Junior e Marcelo Magalhães Peixoto.MP Editora: São Paulo. 2012, pag. 32.

12 Coelho. Fabio Ulhoa. Curso de Direito Comercial. Saraiva: São Paulo. 2014, pag.409. 
A sustentação de Fabio Ulhoa Coelho ${ }^{13}$, ao reconhecer a imprecisão temática, parte da premissa de que o legislador ao disciplinar o instituto, valeu-se exclusivamente de conceitos de direito societário como capital social, denominação social e quotas, referindo-se à Eireli como uma modalidade societária no parágrafo $3^{\circ}$ do art.980-A,

Desta forma, com a aplicação do regime de sociedade limitada, inclina-se este Autor a não considerar esta empresa como uma espécie de pessoa jurídica diferente de sociedade, mas sim, como uma sociedade unipessoal por interpretação sistemática do art. 980-A do Código Civil, concluindo que não se trata de um novo tipo de pessoa jurídica como equivocadamente se poderia depreender da interpretação literal do art. 44,VI, do Código Civil.

A posição de que a Eireli é um novo ente, distinto da sociedade e do empresário, é sustentada também por parte da doutrina como Alfredo de Assis Gonçalves Neto ${ }^{14}$ que aponta certas restriçóes à personalidade jurídica da empresa individual de responsabilidade limitada, do ponto de vista da relaçáo intersubjetiva real haja vista que haveria uma impossibilidade material de o titular da Eireli ser sujeito ativo ou passivo de uma relação jurídica contrária com a empresa que titulariza de forma tal que não se poderia conferir ao credor o direito e o poder de exigir e ao devedor a obrigação e a subsunção a uma coerção que lhe imponha prestar.

O Autor entende que o ato de constituição de uma empresa individual de responsabilidade limitada é uma declaração unilateral de vontade, enquadrando-se, portanto, no gênero dos negócios jurídicos unilaterais e como tal deve ser tratado, afastando-se a normativa dos contratos unilaterais, bilaterais ou plurilaterais ou contrato-organizaçáo, em razão do pressuposto do acordo de vontades para o seu nascimento.

Na I - Jornada de Direito Comercial, organizada ${ }^{15}$ pelo Centro de Estudos Judiciários (CEJ-Brasil), foi aprovado o seguinte Enunciado. "3-A Empresa Individual de Responsabilidade Limitada - EIRELI não é sociedade unipessoal, mas um novo ente, distinto da pessoa do empresário e da sociedade empresária."

A partir do direito projetado, claro estava que a Eireli se constituiria como uma sociedade unipessoal. Todavia, a opção do legislador ao criar a Eireli como o fez, desprezando parte do fundamento daquele projeto de lei, parece que acabou por não constituir um novo tipo social que poderia ser denominado de sociedade unipessoal a exemplo do que ocorreu em países que possuem o Instituto em seu ordenamento, mas sim e tão só, o de gerar uma nova modalidade de pessoa jurídica de direito privado à luz do art.44 VI

13 Coelho, Fábio Ulhoa. Curso de Direito Comercial. Saraiva: São Paulo. 18ª Ed. Vol.2. 2014. pág. 409.

14 Gonçalves Neto. Alfredo de Assis. Direito de Empresa.4a Ed. São Paulo:RT. 2012. pags.121 a 138

15 Ocorrida em outubro de 2012 em Brasília. O autor do Enunciado 3 é o Prof. Maurício Andere Von Bruck Lacerda. 
do Código Civil ${ }^{16}$, para fins estritamente empresariais e com características próprias para o exercício de empresa vista aqui como o exercício da atividade econômica organizada para circulação e produção de bens e serviços ${ }^{17}$.

O fato de no ato constitutivo se poder disciplinar sobre quotas e capital social como previsto no art. 980-A parece-nos que não se pode induzir a premissa de que seja a Eireli, no momento de sua criação, uma sociedade, pois este ente encontra-se no Código Civil em título próprio (Título I-A) quando as sociedades estão todas disciplinadas no Título II.

O conceito de sociedade previsto pelo legislador brasileiro encontra-se no art. 981 do Código Civil que menciona: Celebram contrato de sociedade as pessoas que reciprocamente se obrigam a contribuir, com bens ou serviços, para o exercício de atividade econômica e a partilha, entre si, dos resultados.

$\mathrm{Na}$ Eireli não há nenhuma destas situaçóes e nem tão pouco a existência do affectio societatis, haja vista que o titular interessado, se lança à atividade empresarial de forma individual, todavia, com limitação de responsabilidade e divisão patrimonial, que é o seu grande atrativo.

Desta forma se consegue compreender a unipessoalidade onde é empresária a pessoa jurídica da Eireli que exercita a atividade empresarial e possui, portanto, um patrimônio próprio e específico que será afetado por esta atividade e que, no conjunto de bens corpóreos e incorpóreos, será formado então o seu estabelecimento empresarial como complexo de bens organizados, com regime distinto e específico previsto nos arts. 1.142 e seguintes do Código Civil. A pessoa instituidora ou criadora da Eireli é o seu titular, equiparandose ao sócio de responsabilidade limitada.

Retomando a análise do ato constitutivo da Eireli, como um ato unilateral de vontade, e em sintonia com o disposto no art. 980-A, parágrafo $6^{\circ}$ do Código Civil ${ }^{18}$, ousamos discordar, em parte, do posicionamento doutrinário exposto. Muito embora iniciado por uma pessoa, o ato constitutivo da Eireli, assim como as suas alterações posteriores, deterá na nossa ótica, a natureza jurídica de negócio contratual. Explicamo-nos:

Aparentemente unilateral pelo fato de existir apenas uma pessoa quando da constituição, situação que poderia aproximá-la das fundações e associações, se difere destas radicalmente no que tange a finalidade exclusivamente econômica do ato instituidor, uma vez que efetivada a regular criação da empresa individual de responsabilidade limitada como pessoa jurídica, passará esta, a partir deste ato unilateral e como efeito direto e imediato, a convergir em direitos e obrigaçóes do titularizador para com relação à empresa;

16 Art. 44. Sáo pessoas jurídicas de direito privado VI as empresas individuais de responsabilidade limitada.

17 Vide Art. 966 do código Civil.

18 Art. 980-A - 60 :Aplica-se à empresa individual de responsabilidade limitada, no que couber, as regras previstas para a sociedade limitada. 
desta para com relação ao seu criador e, ainda, nas relaçôes da empresa para com relação aos seus empregados, mercado, terceiros, fornecedores, e demais stackholders ${ }^{19}$, muito se assemelhando ao que Ascarelli ${ }^{20}$ denomina de contrato plurilateral ${ }^{21}$, pelo menos nos efeitos práticos da criação da Eireli.

Esta situação pode também ser verificada, caso se admitisse a sua titularizaçáo por uma pessoa jurídica onde os vetores das relaçóes de caráter obrigacional entâo, se dirigirão da empresa para a pessoa jurídica; da empresa para os sócios da pessoa jurídica e vice versa, aumentando a ideia de plurilateralidade ao limite da imaginação relacionada à livre forma de organização societária, com base no permissivo do Art. 170 da Constituição Federal, no âmbito do princípio da livre iniciativa.

Não se trata aqui de imaginar-se que teria havido uma autocontratação que é vedada pelo art. 117 do Código Civil, mas sim, da comprovação da existência de alteridade quando da constituiçáo da Eireli. Por esta razáo que mencionamos ser meramente aparente o ato unilateral haja vista que, naquele exato momento - com o registro, se viabiliza a criação e nascimento da empresa individual de responsabilidade limitada como ente personalizado distinto e independente.

Em contribuição da posição que adotamos acerca da natureza jurídica da Eireli, rememora-se ainda que a subsidiária integral constituída através de escritura pública efetivada por um único acionista - sociedade brasileira, como preleciona o art. $251 \mathrm{da}$ Lei 6.404/76, possui natureza jurídica de sociedade empresária de direito privado e, no âmbito de suas relações com acionistas e terceiros, a relação poderá se equiparar a relação de contrato, muito embora seu ato instituidor tenha sido efetivado unitariamente de forma pública.

A posição adotada, encontra sintonia com a teoria da pessoa jurídica realidade. José Lamartine Correia de Oliveira ${ }^{22}$, a propósito, busca demonstrar que a personalidade jurídica é uma realidade socialmente ôntica, analógica à personalidade humana. Esta visão teórica da realidade, teve origem germânica e foi construída com base no fato de que tanto a vontade pública como a privada, são capazes de dar vida a um organismo próprio e independente que detem existência própria e distinta da de seus membros, capaz de tornar-se sujeito de direito, real e verdadeiro. A ideia básica desta visão teórica se faz no

19 Aqui no sentido de partes relacionadas à atividade empresarial desenvolvida.

20 ASCARELLI, Tullio. Problemas das sociedades anônimas e direito comparado. Campinas: Bookseller, 2001, p. 388.

21 A propósito deste tema vide Capítulo denominado O Contrato Social na obra de Adalberto Simão Filho. Direito Societário Contemporâneo. Pág.70.

22 OLIVEIRA, José Lamartine Correia de. A dupla crise da pessoa jurídica. São Paulo: Saraiva, 1979, p. 16-20. 
sentido de que as pessoas jurídicas, longe de serem mera ficção, são uma realidade sociológica composta de seres com vida própria, que nascem por imposição das forças sociais.

As pessoas jurídicas são corpos sociais cuja existência é declarada pelo direito e nos seus efeitos finalistas, objetivam a atuação social e econômica da empresa levando ao resultado final desta análise, às mesmas consequências práticas já definidas por Fabio Ulhoa Coelho na sua visão societária da Eireli, todavia,a partir de um outro caminho teórico.

Resumindo, a Eireli, apesar de legalmente ter sido no Brasil concebida como um novo ente, com patrimônio próprio que comporá o seu estabelecimento empresarial, distinto da pessoa do seu titular, quando da sacramentaçáo de seu ato constitutivo pelo registro, passará a deter a natureza de negócio jurídico contratual que, nos efeitos práticos, se aproximará dos contratos plurilaterais de natureza societária, submetendo-se, portanto, às regras da sociedade limitada e, desta forma, aproximando-se da solução espanhola adotada para a SLNE.

\section{Objeto Social}

A SLNE espanhola tem caráter mercantil estatuído por força de lei, independentemente de seu objeto social. Desta forma, uma sociedade deste modelo, mesmo que apenas seja formada como uma holding company de participaçóes, terá o caráter mercantil a demonstrar que a vontade do legislador se fez no sentido de açambarcar nesta modalidade, o maior volume possível de atividades de qualquer natureza, respeitando-se todavia, os limites especificados em lei, como as atividades específicas e reguladas de outra forma, como é o caso daquelas praticadas pelas instituiçôes financeiras, e, ainda, daquelas onde a lei exija que para o seu implemento se constitua uma sociedade por açóes ou aquelas cujo exercício impleque objeto social único e exclusivo.

Já no Brasil, a disciplina jurídica relativa ao objeto social da Eireli deve ser vista de forma ampla a partir do disposto no parágrafo $6^{\circ}$ do art. 980 - A que prevê a aplicação, no que couber, das regras previstas para as sociedades limitadas. Desta forma, o objeto poderá ser tanto mercantil como de serviços, não se podendo mencionar que a mesma só possa se prestar a operar na prestação de serviços voltados para a exploração de atividades decorrente de direitos imateriais ou intelectuais.

O fato de o parágrafo $5^{\circ}$ do art. 980- A - mencionar que poderá ser atribuído à empresa individual de responsabilidade limitada constituída para a prestação de serviços de qualquer natureza, a remuneração decorrente de cessão de direitos patrimoniais do autor ou de imagem, nome, marca ou voz de que seja detentor o titular da pessoa jurídica, vinculado à atividade profissional, não deve ser interpretado como se este ente somente pudesse operar na prestação de serviços ou, ainda, como se a profissionalidade do titular fosse elemento preponderante para a escolha do objeto social. 
Trata-se apenas e tão só de uma faculdade outorgada pela lei, ao titular de direitos imateriais e propriedades industriais que tenham sido objeto de negócios jurídicos com terceiros que redundem em remuneração de qualquer natureza, a seu livre critério organizacional e gerencial, de atribuir à Eireli esta remuneração, talvez como forma de aumento de capital social ou até, de integralização do capital social.

A Eireli pode ser também a própria detentora destes direitos imateriais mencionados, por meio de cessão e transferência advinda do titularizador para a mesma, desta feita, como composição total ou parcial do capital social, passando, portanto, a administrá-los como bem entenda, nos limites atinentes aos mesmos e aos contratos eventualmente existentes.

Observando-se a Eireli com relação à sua natureza jurídica em confronto com o seu objeto, do ponto de vista tributário, Ives Gandra da Silva Martins ${ }^{23}$ ao mencionar que o artigo 109 do CTN determina que nada pode ser mudado no direito provado pela lei ordinária tributária a não ser a definição dos respectivos efeitos tributários, entende que é impossível alterar a natureza das empresas individuais para tratá-las, tributariamente, como se não fossem pessoas jurídicas ou como se nem fossem empresas.

Reconhece como indiscutível, o avanço legislativo que complementa o artigo 129 da lei 11.196/2005, dando-lhe maior extensão do que a que possuía a empresa unipessoal ao admitir, como pessoa jurídica individual de direito privado, qualquer tipo de atividade.

Desta forma, observando-se o principio da livre iniciativa, qualquer objeto social será possível empreender por Eireli e, não há em absoluto qualquer compromisso de profissionalismo por parte do titular para com relação a este objeto social.

\section{Nome Empresarial}

Com as modificaçôes decorrentes da Ley 24/2005, de 18 de novembro sobre a lei originária da SLNE onde a denominação social deste modelo era formada por nomes e sobrenomes de sócios fundadores, possibilitou-se que a constituição da razão social poderia se dar com base no nome e sobrenome de apenas um dos sócios fundadores. Criou-se mais maleabilidade na constituição da denominação social ou da razão social que, posteriormente, poderá ser modificada, a depender dos interesses dos sócios, para que estes possam eleger a melhor forma.

Já no Brasil, como nome empresarial da empresa individual de responsabilidade limitada, o titular se utilizará, a seu livre critério, da firma ou a denominação social com a

23 Martins, Ives Gandra da Silva. Artigo Lei. 12.441 de 11/07/2011. Publicado na obra Empresa individual de Responsabilidade Limitada-Eireli- Aspectos econômicos e legais, organizada por Pedro Anan Junior e Marcelo Magalhães Peixoto.MP Editora.São Paulo, 2012, pag. 105. 
inclusão da expressão "EIRELI" a final ${ }^{24}$, devendo obedecer ao princípio da veracidade e da novidade, incorporando os elementos específicos ou complementares exigidos ou não proibidos em lei.

Quando adotar firma, esta será formada com o seu próprio nome, que deverá figurar de forma completa, podendo ser abreviados os prenomes. Caso exista nome empresarial idêntico, poderá aditar designação mais precisa de sua pessoa ou de sua atividade.

Ao adotar a denominação social, esta poderá conter o seu nome e designar o objeto da empresa, de modo específico, não se admitindo expressóes genéricas isoladas, como: comércio, indústria, serviços.

Caso exista mais de uma atividade como objeto social, poderá ser escolhida uma ou mais dentre estas, para compor a denominação social. Caso se apresentar para arquivamento uma declaração de enquadramento como microempresa ou empresa de pequeno porte de forma simultânea ao ato constitutivo, é facultativa a indicação do objeto (atividade) na denominação.

Todavia, a adição ao nome empresarial da EIRELI, da expressão ME ou MICROEMPRESA e EPP ou EMPRESA DE PEQUENO PORTE, não pode ser efetuada diretamente no ato constitutivo, mas, depois de procedido o arquivamento deste pela Junta Comercial e procedido o enquadramento da EIRELI na condição de microempresa, ou empresa de pequeno porte, mediante declaração em instrumento próprio para essa finalidade. Finalizando, nos atos sociais subsequentes, se deve fazer a adição de tais termos ao nome empresarial ${ }^{25}$.

\section{Análise do Capital Social}

$\mathrm{Na}$ SLNE o capital social não poderá ser inferior a tres mil euros e nem tampouco superior a cento e vinte mil euros. Não se adimite outra forma de aporte de capital a não ser em moeda corrente.

A disciplina de capital social da Eireli no Brasil foi regulada no art. 980 - A, nos seguintes termos: A empresa individual de responsabilidade limitada será constituida por uma única pessoa titular da totalidade do capital social, devidamente integralizado, que não será inferior a 100 (cem) vezes o maior salário minimo vigente no pais.

24 A Instrução Normativa n 177, de 22 de novembro de 2011 do Departamento Nacional do Registro de Comércio, aprovou o Manual dos atos de Registro de Empresa Individual de Responsabilidade Limitada para que o mesmo possa ser observado por todas as juntas comerciais do pais e, neste manual há previsóes completas sobre o nome empresarial e os demais assuntos pertinentes a este ente.

25 Como previsto no Manual de Atos de Registro de Empresa Individual de Responsabilidade Limitada criado pela Instruçấo Normativa n.117 de 22 de novembro de 2011. 
Esta exigência de valor inicial de capital integralizado gerou um forte movimento social $^{26}$ e há quem entenda que realmente esta estipulação valorativa é inconstitucional como Paulo Roberto Pedro Bastos ${ }^{27}$ que disserta no sentido de que esta fixação de valor mínimo pela lei seria inconstitucional e deporia contra o principio da livre iniciativa e livre fixação do capital social.

Por sua vez, H.Philip Schneider e Laura Benini Candido ${ }^{28}$ apesar de entenderem que a figura do capital mínimo foi criada para tutelar a garantia dos credores como contrapartida à limitação de responsabilidade, são da opinião de que esta exigência não constitui um mecanismo efetivo para a garantia dos credores e não evita a utilização do tipo social para fraude.

Divergimos desta visão haja vista que é faculdade do empresário adequar-se ao sistema que mais lhe atende, a depender do nível de investimento pretendido na atividade. Já mencionou-se em outra oportunidade, ${ }^{29}$ que o capital social tem uma funçáo duplice, podendo tanto ser somatória das contribuições de responsabilidade dos sócios para que a sociedade possa bem cumprir o seu objetivo social como tambem se transformar num elemento de segurança para os credores da sociedade, na medida em que não é permitido aos sócios a distribuição de quantias ou valores necessários para a mantença da integridade do mesmo, haja vista a sua necessidade de estabilidade e intangíbilidade refletida na norma do art. 1.059 do Código Civil que expressa no sentido de obrigar aos sócios a reposiçáo dos lucros e das quantias retiradas a qualquer título, ainda que autorizados pelo contrato, quando tais lucros ou quantia se distribuirem com prejuízo do capital social.

26 O PPS (Partido Popular Socialista) ajuizou Ação Direta de Inconstitucionalidade (ADI 4637) no Supremo Tribunal Federal (STF) contra a parte final do caput do artigo 980-A do Código Civil (Lei 10.406, de 10 de janeiro de 2002), que exige um capital social de pelo menos 100 salários mínimos, o que hoje equivale a $\mathrm{R} \$ 54,5$ mil, para a criação de uma empresa individual de responsabilidade limitada. $\mathrm{O}$ dispositivo legal foi alterado em 2011 pelo artigo $2^{\circ}$ da Lei 12.441. Segundo a agremiação partidária, "o salário mínimo não pode ser utilizado como critério de indexaçáo para a determinaçáo do capital mínimo necessário para a abertura de empresas individuais de responsabilidade limitada”. O partido frisa que "tal exigência esbarra na notória vedação de vinculação do salário mínimo para qualquer fim, prevista no inciso IV do artigo $7^{\circ}$ da Constituição Federal”.

27 Pedro, Paulo Roberto Bastos. Curso de Direito Empresarial. RT:Sáo Paulo.2014 Pág. 48. O projeto de Lei 4.605 de 2009 de lavra do Deputado Marcos Montes náo previa a exigência de capital mínimo na Eireli .Esta exigência decorreu de inserção efetuada por meio do Relatório da Comissão de Constituição e Justiça e de Cidadania (“CCJ”) pelo Deputado Marcelo Itagiba, sob o argumento de se afastar possíveis fraudes que pudessem desvirtuar a iniciativa.

28 Schneider. H.Philip e Laura Benini Candido. Importância da exigência do capital mínimo para constituição de Eireli., Publicado na obra Empresa individual de Responsabilidade Limitada-EireliAspectos econômicos e legais, organizada por Pedro Anan Junior e Marcelo Magalhães Peixoto.MP Editora.São Paulo, 2012, pag. 89. Os autores informam acerca do Projeto de Lei n. 2.468/2011 proposto pelo deputado Carlos Bezerra para a reduçáo do valor do capital social da Eireli para 50 (cinquenta) vezes o valor do maior salário mínimo vigente no Pais, a demonstrar a impropriedade e o excesso da obrigação originária.pág.102.

29 Simão Filho, Adalberto. Direito empresarial Contemporâneo. Saraiva:São Paulo. 2012. 
A função econômica do capital relaciona-se com a própria capacidade da sociedade para operar e funcionar com vistas à realização do objeto social, possuindo assim, duas funçôes básicas como preleciona Carlos Fulgencio da Cunha Peixoto ${ }^{30}$ a saber: função interna: fixa a relação patrimonial entre os sócios e regula a participação social nos lucros e nos riscos, na conformidade da contribuição social; função externa: representa o capital social a segurança dos terceiros que com a sociedade entabulem negócios jurídicos, na medida em que não é permitido pela lei a distribuição do capital entre os sócios, haja vista a intangibilidade do capítal social.

O capital social forma o patrimonio inicial da sociedade que não se confunde com o fundo social que é formado pelo patrimonio social. E isto porque o capital permanecerá estático no curso das atividades sociais até o momento de sua correção, atualização ou aumento ao passo que o fundo social poderá aumentar na razáo do crescimento do patrimonio social e do próprio estabelecimento.

Sobre o sentido da expressão patrimonio social, como elemento de distinçáo entre capital social pode-se observar que a primeira representa um fator ideal constante e o segundo um fundo real variável, onde somente se concretiza uma cifra após o levantamento do balanço efetuado em dado momento. Ferrer Correa ${ }^{31}$ propóe a seguinte devisão do patrimonio: patrimonio bruto: É o conjunto dos direitos avaliáveis em dinheiro, de que a sociedade é titular num dado momento, mais a somatória de suas dívidas;patrimonio ilíquido: Engloba o conjunto dos elementos ativos da sociedade, sem considerar o passivo e patrimonio liquido: Determina o valor do ativo após o desconto das contas passivas.

Finalmente, as regras estabelecidas pelo Manual aprovado pela Instrução Normativa n.117 de 22 de novembro de 2011 do DNRC, sobre o capital social e a sua integralizaçáo, podem ser sintetizadas da seguinte forma.

i) Expressáo do capital: $\mathrm{O}$ capital não precisa ser dividido em quotas e deve ser expresso em moeda corrente, equivalente a, pelo menos, 100 (cem) vezes o maior salário mínimo vigente no País (art. 980-A, CC/2002), inteiramente integralizado na constituição ou em aumentos.

ii) Integralização com bens: Poderão ser utilizados para integralização de capital quaisquer bens, desde que suscetíveis de avaliação em dinheiro.

iii) Integralização com imóveis: No caso de imóvel, ou direitos a ele relativo, o ato constitutivo, por instrumento público ou particular, deverá conter sua descrição, identificação, área, dados relativos à sua titulação, bem como o número

30 Peixoto, Carlos Fulgêncio da Cunha. A sociedade por cotas de responsabilidade limitada. 2a ed. Vol, Forense: Rio de Janeiro. 1958.

31 CORREIA, Ferrer A. Lições de direito comercial. Lisboa: Lex ediçôes jurídicas:. 1994. 
de sua matrícula no Registro Imobiliário. No caso de titular casado, deverá haver a anuência do cônjuge, salvo no regime de separação absoluta.

iv) Integralizaçáo com participaçóes sociais: A integralização de capital com quotas de determinada sociedade implicará na correspondente alteração do contrato social modificando o quadro societário da sociedade cujas quotas foram conferidas para integralizar o capital, consignando a saída do sócio e ingresso da Eireli que passa a ser titular das quotas. Se as sedes das empresas envolvidas estiverem situadas na mesma unidade da federação, os respectivos processos de constituição e de alteração tramitarão vinculados. Caso estejam sediadas em unidades da federação diferentes, deverá ser primeiramente, promovido o arquivamento do ato constitutivo e, em seguida, promovida a alteração contratual de substituição de sócio.

v) Inexigibilidade de avaliação prévia. Não é exigível a apresentação de laudo de avaliação para comprovação dos valores dos bens declarados na integralização de capital de Eireli.

Demonstra-se desta forma, o relevo do estudo do capital social na tipologia empresarial onde prepondera a responsabilidade limitada de sócios pelas obrigaçóes sociais.

\section{Da Administração}

A exemplo das sociedades de responsabilidade limitada espanholas, na SLNE também funciona uma junta geral cuja função é compor os órgãos sociais como poder supremo. A administração deste tipo social poderá ser formada tanto por um órgão de caráter unipessoal como pluripessoal. Todavia, há certos impedimentos pois náo se deve adotar a forma e nem tampouco, o regime de funcionamento do Conselho de Administração. A administração é apanágio de sócios.

A administração da Eireli , por sua vez, será organizada na forma como preconizar o seu titular, observando os parâmetros e condicionantes legais. Poderá ser exercida por uma ou mais pessoas designadas no ato constitutivo, podendo ser o seu titular ou terceiros. Caso o administrador seja nomeado na constituição e arquivamento do ato de sua nomeação, não será exigível a apresentação do termo de posse.

Facultativa é a previsão de prazo do mandato de administrador. Não estando previsto, entender-se-á ser de prazo indeterminado. $\mathrm{O}$ administrador não titular considerar-se-á investido no cargo mediante aposiçáo de sua assinatura no ato constitutivo em que foi nomeado. A declaração de inexistência de impedimento para o exercício de administração, se não constar do ato constitutivo, deverá ser apresentada em ato separado, que instruirá o processo. 
A Administração de Eireli por pessoa jurídica encontra vedação expressa no Manual de Instituição deste ente, aprovado pela Instrução Normativa do DNRC.

Em caso de se indicar um Administrador estrangeiro, este deverá ter visto permanente e não estar enquadrado nas situaçôes de impedimento para o exercício da administração.

Finalmente, o Administrador sujeitar-se-á às regras de responsabilidade previstas na sociedade limitada.

\section{Características Principais dos Modelos}

\section{i) O modelo espanhol SLNE}

Admissão do caráter unipessoal com responsabilidade limitada

Limitação de responsabilidade econômica dos sócios;

Não cabe conselho de administração;

Administrador deve ser sócio;

Existência de capital social Maximo.

Impossibilidade de se utilizar de denominação social completa e objetiva no momento da constituição.

Numero Maximo de 05 sócios na constituiçáo.

Facilitação de ajustes tributários em face de previsão legal do modelo.

Facilidade de criação e registro deste tipo social. (por via telemática em até 48 horas ou por via ordinária)

Não há número mínimo de sócios trabalhadores.

Não se admite constituir por um sócio mais de uma sociedade desta natureza.

Se pode controlar a entrada de pessoas estranhas ao quadro social (intuito personae)

Possibilidade de fixar salário ao sócio de trabalho.

Ampla liberdade de pactos e ajustes entre sócios.

Clareza do regime jurídico

\section{ii) $\mathrm{O}$ modelo brasileiro Eireli}

Admissão de titularização por pessoa física, apontando a nacionalidade, estado civil, profissão, residência.

Ente único. O seu titular, não pode participar de nenhuma outra empresa dessa modalidade. 
Capital social mínimo expresso em moeda corrente, equivalente a, pelo menos, 100 (cem) vezes o maior salário mínimo vigente no País (art. 980A, CC/2002) e devidamente integralizado;

Unicidade do capital: Por ser detido por apenas um titular, o capital da Eireli não precisa ser dividido em quotas.

Valor mínimo do capital e integralização. O capital da Eireli deve estar inteiramente integralizado na constituição ou em aumento futuros. Declaração de integralização de todo o capital em bens ou dinheiro (art. 980-A, CC/2002);

Nome empresarial. A finalização do mesmo será com a expressão Eirele.

Objeto social. O objeto não poderá ser ilícito, impossível, indeterminado ou indeterminável, ou contrário aos bons costumes, à ordem pública ou à moral. $\mathrm{O}$ ato constitutivo deverá indicar com precisão e clareza as atividades a serem desenvolvidas pela empresa, sendo vedada a inserçáo de termos estrangeiros, exceto quando não houver termo correspondente em português ou já incorporado ao vernáculo nacional.

Prazo de duração da empresa: Pode ser indeterminado.

Administração. Pessoa(s) natural (is) são incumbida(s) da administração da empresa, e seus poderes e atribuiçôes; e qualificação do administrador, caso não seja o titular da empresa devem estar informados. Sendo os administradores nomeados no ato constitutivo, é obrigatória a indicação de seus poderes e atribuiçôes.

Declaração de desimpedimento. declaraçáo, sob as penas da lei, de que o administrador não está impedido, por lei especial, e nem condenado ou encontrar-se sob os efeitos de condenação, que o proíba de exercer a administração de empresa individual de responsabilidade limitada;

Atos privativos ou dependentes. Atos privativos ou que dependam de aprovação prévia do titular da empresa para que possam ser adotados pela administração (por exemplo, assinatura de contratos acima de determinado valor, alienação de ativos etc.);

Órgãos sociais. Atos de gestão relacionados à criação, formação e ao funcionamento de órgãos sociais. Caso o Titular pretenda criar diretorias, gerencias, designar prepostos ou auxiliares.

Atos facultativos. Qualquer outro ato de interesse do titular da empresa para a obtenção do fim social e cumprimento do objeto social.

\section{Conclusões}

A análise comparativa efetivada de forma singela neste artigo, demonstra que a limitação de responsabilidade daquele que queira empreender em forma singular ou coletiva, 
longe de se transformar num sistema de auxílio à fraude como em certa época se cogitou, traz a real perspectiva de proporcionar o fomento da atividade mercantil através da criaçáo de ambiente propício para a inversão de capitais e de negócios.

A criaçáo de novos modelos que possam gerar ao empresário a segurança e a boa administraçáo do risco destinado à atividade empresarial, faz com que o interesse se aumente e o mercado se harmonize pois, com regras claras todos conhecem as suas responsabilidades.

A lei espanhola possui avanços em relação à legislação brasileira de Eireli por ser mais completa e por abordar a possibilidade de se constituir sociedade pluripessoal a partir de uma sociedade que originariamente se pretendeu unipessoal, sem que se modifique as caracteristicas da pessoa jurídica.

O capital social mínimo do modelo espanhol aliado ao fato de suas facilidades registrarias e tributárias, serão elementos de atração poderosos para aqueles que pretenderem se lançar na atividade mercantil.

Já no Brasil, mesmo que a criaçáo da empresa individual de responsabilidade limitada possa náo ter se materializado com todo o vigor legislativo do projeto, como informado, é certo que as poucas normas a respeito, que se transformaram em uma realidade e em mais uma opção ao empreendedor, parecem suficientes para gerar uma interpretaçáo sistêmica a considerar a função econômica e social deste instituto.

Limitar responsabilidades de empreendedores, não significa gerar uma condição de fraude ou de simulaçẫo a partir da atividade empresarial, mas sim e tão só, dar a condição de segurança para que os capitais possam se voltar para a economia pátria, respeitando-se um conceito claro e esperado de real limitação de responsabilidade, àquele que venha a inverter seus esforços e recursos numa atividade empresarial.

A empresa individual de responsabilidade limitada, poderá bem cumprir este papel. O desafio maior será o da interpretaçáo da norma em face dos fatos e valores do nosso tempo. Se se pretende a criação de um ambiente de negócios e de investimentos no pais, há que se ter uma interpretação aberta, acerca das poucas regras de constituição deste novo ente.

E é dentro deste espírito que defendeu-se neste artigo a possibilidade de pessoa jurídica ser a titular e criadora da empresa individual de responsabilidade limitada, como parte de seu livre direito de organização e gestão da atividade empreendida, na forma como melhor the parecer. Todavia, sobre este tema, há que se respeitar os ditames do D.N.R.C. para quem somente uma pessoa natural poderá titularizar um ente desta natureza, ou ainda, aguardar o que for definido no futuro pela jurisprudência pátria sobre a espécie.

Os países tem muitas experiências a trocar no campo das inovaçóes que apresentaram e quanto mais oportunidades se proporcionar para o fomento e incremento da 
atividade empresarial, clareando as condições de exercício, delimitando responsabilidades, ofertando condiçóes reais de crescimento, criando sistemas apropriados para gerar a transformação de tipos sociais ou a criação de mais empresas ou sociedades quie claramente possam definir responsabilidades de sócios, mais pessoas serão atraídas à atividade empresarial, tornando-se competitivas e eficientes, com acesso a capitais, melhorando a possibilidade da produção e circulação de riquezas. A geração da inclusão social por meio da atividade empresarial, proporcionará mais empregos e o desenvolvimento com sustentabilidade das relaçóes empresariais, econômicas humanas e sociais.

\section{Referências}

ARAGÃO, Paulo Cesar e DA CRUZ, Gisela Sampaio. Empresa individual de responsabilidade limitada: O "moderno Prometheus" do direito societário. Publicado na obra Empresa individual de Responsabilidade Limitada-Eireli- Aspectos econômicos e legais, organizada por Pedro Anan Junior e Marcelo Magalhães Peixoto. São Paulo: MP Editora, 2012.

ASCARELLI, Tullio. Problemas das sociedades anônimas e direito comparado. Campinas: Bookseller, 2001.

COELHO.Fabio Ulhoa. Curso de Direito Comercial. São Paulo: Saraiva 18a Ed, Vol.2, 2014.

CORREIA,Ferrer A.Liçóes de direito comercial. Lisboa: Lex ediçôes jurídicas:. 1994.

DORNELES, Francisco. Novas perspectivas para os empreendedores brasileiros. Publicado na obra Empresa individual de Responsabilidade Limitada-Eireli- Aspectos econômicos e legais, organizada por Pedro Anan Junior e Marcelo Magalhães Peixoto. São Paulo: MP Editora. 2012

GONÇALVES NETO. Alfredo de Assis. Direito de empresa. São Paulo: Revista dos Tribunais, 4a Ed.2014.

LACERDA, Maurício Andere Von Bruck Empresa Individual de responsabilidade Limitada- Eire li. Desafios e Perspectivas, artigo publicado na Revista eletrônica FMU Direito, ano 27, n.39, p.151, 2013.

MACNAUGHTON, Charles William, in Titular estrangeiro na Eireli. Publicado na obra Empresa individual de Responsabilidade Limitada-Eireli- Aspectos econômicos e legais, organizada por Pedro Anan Junior e Marcelo Magalhães Peixoto. São Paulo: MP Editora, 2012.

MARTINS, Ives Gandra da Silva. Artigo Lein. 12.441 de 11/07/2011. Publicado na obra Empresa individual de Responsabilidade Limitada-Eireli- Aspectos econômicos e 
legais, organizada por Pedro Anan Junior e Marcelo Magalhães Peixoto. São Paulo: MP Editora, 2012.

NUNES, Márcio Tadeu Guimarães. EIRELI- A Tutela do patrimônio de afetação. São Paulo: Quartier Latin, 2014.

OLIVEIRA, José Lamartine Correia de. A dupla crise da pessoa jurídica. São Paulo: Saraiva 1979.

PEIXOTO, Carlos Fulgêncio da Cunha. A sociedade por cotas de responsabilidade limitada. $2^{\text {a }}$ ed.Vol, Rio de Janeiro: Forense, 1958.

PASTORE Ana Claudia e SIMÃO FILHO, Adalberto. In Aplicabilidade da convenção arbitral no âmbito da empresa individual de responsabilidade limitada. Artigo publicado na obra Empresa Individual de Responsabilidade Limitada- Eireli- Aspectos Econômicos e legais, org. Pedro Anan Junior e Marcelo Magalhães Peixoto. São Paulo:MP Editora, 2012.

PEDRO, Paulo Roberto Bastos. Curso de Direito Empresarial. São Paulo: Revista dos Tribunais, 2014.

SCHNEIDER, H.Philip e CANDIDO, Laura Benini. Importância da exigência do capital mínimo para constituição de Eire li, Publicado na obra Empresa individual de Responsabilidade Limitada-Eireli- Aspectos econômicos e legais, organizada por Pedro Anan Junior e Marcelo Magalhães Peixoto. São Paulo: MP Editora, 2012.

SIMÃO FILHO, Adalberto. Direito Societário Contemporâneo. São Paulo:Saraiva. 2012. 